\title{
THE EFFECT OF SUPPORT PLATE ON DRILLING-INDUCED DELAMINATION
}

\author{
NAVID Zarif Karimi ${ }^{a, *}$, Hossein Heidary ${ }^{b}$, PARnian KianfaR ${ }^{c}$, \\ Mahmud Hasani ${ }^{c}$, Giangiacomo MinaK $^{a}$ \\ a University of Bologna, Via Fontanelle 40, Forli, Italy \\ ${ }^{b}$ University of Tafresh, Tehran Road 1, Tafresh, Iran \\ ${ }^{c}$ Amirkabir University of Technology, Hafez 424, Tehran, Iran \\ * corresponding author: navid.zarif@unibo.it
}

\begin{abstract}
Delamination is considered as a major problem in drilling of composite materials, which degrades the mechanical properties of these materials. The thrust force exerted by the drill is considered as the major cause of delamination; and one practical approach to reduce delamination is to use a back-up plate under the specimen. In this paper, the effect of exit support plate on delamination in twist drilling of glass fiber reinforced composites is studied. Firstly, two analytical models based on linear fracture mechanics and elastic bending theory of plates are described to find critical thrust forces at the beginning of crack growth for drilling with and without back-up plate. Secondly, two series of experiments are carried out on glass fiber reinforced composites to determine quantitatively the effect of drilling parameters on the amount of delamination. Experimental findings verify a large reduction in the amount of delaminated area when a back-up plate is placed under the specimen.
\end{abstract}

KEYWORDS: drilling, composite materials, delamination, support plate.

\section{INTRODUCTION}

Glass fiber reinforced plastics (GFRPs) have been extensively employed in many engineering applications because of their outstanding advantages over other materials. The machining and specially drilling of GPRPs have become very important due to the need for assembling of subcomponents made from these materials. But, composite materials are difficult to machine due to some particular characteristics of them like non-homogeneous, anisotropic and abrasive fibers. This causes significant damages in drilling process such as matrix cracking, fiber breakage, fuzzing and thermal degradation. Among the damages caused by drilling, delamination is considered as one the most crucial, which results in lowering of strength against fatigue and subsequently reducing the longterm performance of composite structures [1, 2,

Several techniques have been suggested to reduce delamination in drilling process that each has its own advantages and limitations. One of the frequently used methods is to place a support plate under the specimen. During supported drilling, in contrast to unsupported drilling, the specimen is not free to bend due to constraints imposed by back-up plate. In drilling with back-up plate, the thrust force increases suddenly and severely as the chisel edge begins to penetrate into the specimen and it continues until the full penetration of cutting lips. At this point actual material removal takes place and the force reaches its steady state value, until delamination occurs. In this stage, delamination causes the force to decrease stepwise, each step associates to a crack opening. Unlike sup- ported drilling, during drilling without back-up plate, the force increases gradually at the beginning of process. This is mainly because the real feed rate is much lower than the adjusted feed due to relative movement of drill bit and workpiece. As the drill bit approaches the last uncut plies, the stress due to the thrust force exceeds its critical value and all the uncut material is burst open [3].

Until now, many researchers have attempted to reduce drilling induced delamination. Hocheng and Dharan used linear elastic fracture mechanics to determine the critical thrust force for twist drilling as push-out delamination begins to propagate 4. Hocheng and Tsao proposed some analytical models for different drill bits including candle stick drill, saw drill, core drill and step drill to determine the thrust force at the beginning of delamination growth [5, 6]. Based on these models, they realized the delamination can be reduced by lowering the thrust force or distributing the force outward from the center 7]. In a similar work, they studied the effect of exit back-up plate on drilling-induced delamination when using a slot drill bit and a core drill bit [8]. They showed that the critical thrust force is increased when using a back-up plate, hence delamination is less likely to happen.

Many efforts have been made to reduce the thrust force exerted by drill bit on the specimen, while few researchers studied the effect of support plate on thrust force and associated delamination. This paper investigates the effect of back-up plate on drilling-induced delamination both analytically and experimentally. 


\section{Experimental Procedure}

\subsection{Delamination Measurement}

Chen presented an index to evaluate the amount of delamination called conventional delamination factor [9]. However, this factor is not proper because the crack size does not represent the damage magnitude appropriately and also this procedure does not indicate the damage area. Davim et al. suggested a superior approach to determine the delamination factor called the adjusted delamination factor $F_{d a}$ which is expressed as Eq. (1) [10]. The first part of Eq. (1) shows the size of the crack contribution and the second part shows the damage area contribution.

$$
F_{d a}=\alpha \frac{D_{\max }}{D_{0}}+\beta \frac{A_{\max }}{A_{0}}
$$

where the coefficients $\alpha$ and $\beta$ can be calculated as below:

$$
\beta=\frac{A_{d}}{A_{0}-A_{\max }} \quad \alpha=1-\beta
$$

where $D_{0}$ is the nominal diameter of the hole, $D_{\max }$ is the maximum diameter of the damage hole, $A_{0}$ is the area related to the nominal hole, $A_{\max }$ is the area related to the maximum diameter of the delamination zone and $A_{d}$ is the delaminated area.

\subsection{Materials AND TOOLS}

The composite plates were produced by hand lay-up method with araldite LY556 epoxy resin reinforced with $60 \%$ E-glass unidirectional fiber. The density of epoxy resin and glass fibers were $1.12 \mathrm{~g} / \mathrm{cm}^{3}$ and $292 \mathrm{~g} / \mathrm{m}^{2}$, respectively. Tensile strength and tensile modules of resin were $80 \mathrm{MPa}$ and $2.7 \mathrm{GPa}$, respectively, and for glass fibers were $2150 \mathrm{MPa}$ and $74 \mathrm{GPa}$, respectively. The composite laminates had 16 plies and a thickness of $5 \mathrm{~mm}$. The holes were drilled at the center of plates by standard HSS twist drills $10 \mathrm{~mm}$. During unsupported drilling, a back-up plate of $5 \mathrm{~mm}$ thick was positioned under the specimens. An appropriate clamping system was used to fix the specimens and back-up plate in the drilling machine, shown in Figure 1. The specimens and back-up plate were fixed in position by tightening four screws at the corners.

\subsection{Plan of Experiments}

In the present study, Taguchi method was used to design drilling experiments. Three parameters, feed rate, cutting speed and drill point angle were selected and three levels for each parameter were suggested based on our preliminary researches [11-14]. After determination of parameters and correspond levels, a proper orthogonal array need to be selected. The orthogonal array chosen was the $L_{9}$.

After conducting experiments, the signal to noise ratio $(S N)$ needs to be calculated for each experiment to determine the effect of each parameter. According

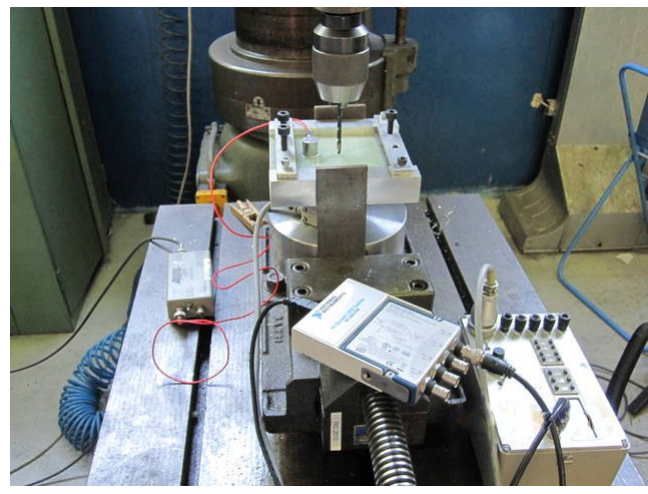

Figure 1. Experimental setup.

to this method, the optimization is done by using three signal to noise ratios; smaller is better, larger is better and nominal is better. Notice that, regardless of what approach is taken, always higher value of the signal to noise ratio is better. In this investigation, the delamination factor needs to be minimized; hence, smaller is better definition of the signal to noise ratio was used.

$$
S N_{i}=-10 \log \left(\sum_{i=1}^{N_{i}} \frac{y_{i}^{2}}{N_{i}}\right)
$$

where $i$ is the experiment number and $N_{i}$ is the number of trials for experiment $i$ [15].

\section{Results And Discussion}

\subsection{Theoretical Analysis of Critical Thrust Force}

The energy balance equation at the onset of delamination propagation is:

$$
d U_{d}=d W-d U
$$

in which $d U$ is the infinitesimal strain energy, $d W$ is the infinitesimal work done by the thrust force $F_{t h}$ and drill displacement of $d X$ and $d U_{d}$ is the infinitesimal strain energy absorbed by crack growth which are as following:

$$
d W=F_{t h} \cdot d X \quad d U_{d}=G_{I C} \cdot d A
$$

where $d A$ is the change in the delamination area and $G_{I C}$ is the critical strain energy release rate in mode I, which is assumed to be constant according to Saghizadeh and Dharan [16].

\subsubsection{Critical Thrust Force in Drilling Without Support Plate}

Figure 2 depicts the schematic of delamination in unsupported drilling. In Figure 2, $F_{t h}$ is the thrust force exerted by a twist drill at the center of plate, $X$ is the displacement of drill, $H$ is the thickness of 


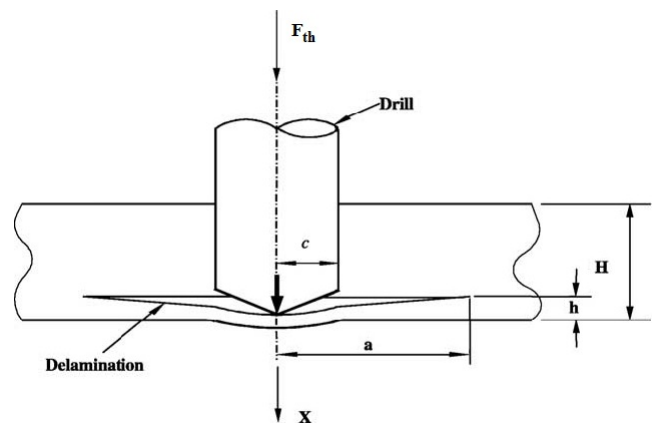

FIGURE 2. The schematic of delamination for unsupported drilling.

specimen, $h$ is the uncut depth under tool, and $a$ is the radius of crack (delamination). In this model, two assumption are considered; the isotropic behavior and pure bending of the laminate. According to the classical plate theory, for a circular plate with clamped edges and concentrated force the amount of deflection can be expressed as [17]:

$$
w(r)=\frac{F_{t h}}{16 \pi M}\left[2 r^{2} \ln \frac{r}{a}+\left(a^{2}-r^{2}\right)\right]
$$

which is written in polar coordinate system ( $r$ is radius). $M=E h^{3} /\left(12\left(1-\vartheta^{2}\right)\right)$ is flexural rigidity of the plate, $E$ is modulus of Young, and $\vartheta$ is ratio of Poisson. The stored strain energy, the work done and the strain energy absorbed by crack growth are expressed as below equations, respectively.

$$
\begin{gathered}
U=\frac{F_{t h}^{2} a^{2}}{32 \pi M} \quad d U=\frac{F_{t h}^{2} a}{16 \pi M} d a \\
W=F_{t h} w(0)=\frac{F_{t h}^{2} a^{2}}{16 \pi M} \quad d W=\frac{F_{t h}^{2} a}{8 \pi M} d a \\
U_{d}=G_{I C} \cdot A=G_{I C} \pi a^{2} \quad d U_{d}=G_{I C} 2 \pi a d a
\end{gathered}
$$

Now it is possible to calculate the critical thrust force at the onset of crack propagation by replacing Eqs. (7), (8) and (9) in the energy balance Eq. (4) as shown below:

$$
F_{t h}=\pi \sqrt{32 G_{I C} M}
$$

In order to prevent delamination, the thrust force exerted by the drill bit on the specimen which is related to the material properties and the uncut thickness should not go over this value.

\subsubsection{Critical Thrust Force in Drilling With Support Plate}

Figure 3 depicts the schematic of delamination in drilling with back-up plate. In Figure $3, F_{B}$ is the thrust force with back-up, $R$ is the upward reaction force from the back-up plate, $b$ is the radius of the applied ring force of back-up and $c$ is the drill radius, $X$ is the displacement. For an edge clamped circular plate under the action of a concentrated force in center and upward circular force, the amount of deflection can be expressed as:

$$
\begin{array}{r}
w_{1}(r)=\frac{F_{B}}{16 \pi M}\left[2 r^{2} \ln \frac{r}{a}+\left(a^{2}-r^{2}\right)\right]- \\
-\frac{R}{8 \pi M}\left[\left(r^{2}+b^{2}\right) \ln \frac{b}{a}+\frac{1}{2}\left(1-\frac{b^{2}}{a^{2}}\right)\left(a^{2}+r^{2}\right)\right] \\
0 \leqslant r \leqslant b
\end{array}
$$

$$
\begin{array}{r}
w_{2}(r)=\frac{F_{B}}{16 \pi M}\left[2 r^{2} \ln \frac{r}{a}+\left(a^{2}-r^{2}\right)\right]- \\
-\frac{R}{8 \pi M}\left[\left(r^{2}+b^{2}\right) \ln \frac{r}{a}+\frac{1}{2}\left(1+\frac{b^{2}}{a^{2}}\right)\left(a^{2}-r^{2}\right)\right] \\
b \leqslant r \leqslant a
\end{array}
$$

using boundary conditions, $w(b)=0$, we get:

$$
R=F_{B} \frac{\left[b^{2} \ln \frac{b}{a}+\left(\frac{b^{2}-a^{2}}{2}\right)\right]}{\left[2 b^{2} \ln \frac{b}{a}+\left(\frac{a^{4}-b^{4}}{2 a^{2}}\right)\right]}
$$

by replacing $R$ into the plate deflection equations, Eq. (11) and Eq. (12), the total stored strain energy and work done by external forces can be derived as follow:

$$
\begin{array}{r}
U=\pi\left[\int_{0}^{b}\left[M\left(\frac{\partial^{2} w_{1}}{\partial r^{2}}+\frac{1}{r} \frac{\partial w_{1}}{\partial r}\right)^{2}\right] r d r+\right. \\
\left.+\int_{b}^{a}\left[M\left(\frac{\partial^{2} w_{2}}{\partial r^{2}}+\frac{1}{r} \frac{\partial w_{2}}{\partial r}\right)^{2}\right] r d r\right] \\
d U=\frac{\partial U}{\partial a} d a
\end{array}
$$

$$
\begin{aligned}
& W=F_{B} w(0)=F_{B}\left[\frac{F_{B} a^{2}}{16 \pi M}-\frac{R}{8 \pi M}\left(b^{2} \ln \frac{b}{a}+\right.\right. \\
& \left.\left.+\left(\frac{a^{2}-b^{2}}{2}\right)\right)\right] \\
& d W=\left(\frac{F_{B}^{2} a}{8 \pi M}-\frac{R F_{B}}{8 \pi M} \frac{a^{2}-b^{2}}{a}\right) d a
\end{aligned}
$$

finally, by calculating $d U_{d}$ from Eq. (14) and replacing $d U_{d}$ and $d W$ in the energy balance equation, Eq. (4), we get:

$$
F_{B}=\pi \sqrt{32 G_{I C} M \frac{B}{A}}
$$

where $A$ and $B$ are defined as follow: 


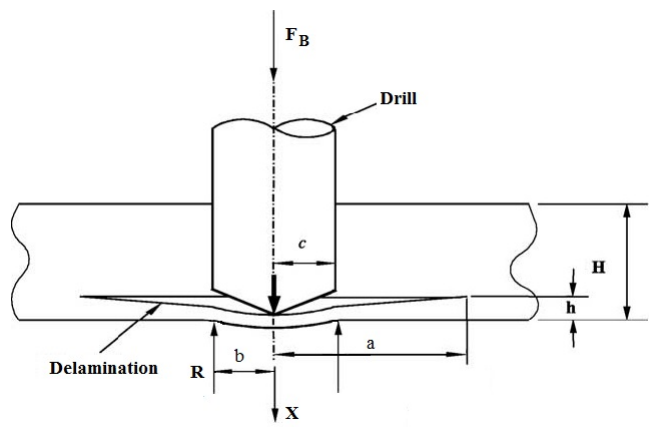

Figure 3. The schematic of delamination for supported drilling.

$$
\begin{aligned}
B & =\left[a^{4}-b^{4}-8 a^{2} b^{2} \ln \frac{b}{a}\right] \times \\
& \times\left[64 b^{4} a^{4} \ln \left(a^{2} b^{2}\right)-128 a^{4} b^{4} \ln b \ln a+16 a^{6} b^{2} \ln \frac{b}{a}+\right. \\
& \left.+16 a^{2} b^{6} \ln \frac{a}{b}+a^{8}+b^{8}-2 a^{4} b^{4}\right]
\end{aligned}
$$

$$
\begin{aligned}
A & =3\left(a^{12}-b^{12}\right)+72 a^{10} b^{2} \ln \frac{b}{a}+192 a^{4} b^{8} \ln a \ln b+ \\
& +3072 a^{6} b^{6} \ln \frac{a^{2}+b}{b^{2}+a}+768 a^{4} b^{8} \ln \frac{a^{2}+b}{b^{2}+a}- \\
& -288 a^{8} b^{4} \ln a \ln b-704 a^{6} b^{6} \ln b+192 a^{2} b^{10} \ln a \ln b+ \\
& +73 a^{4} b^{4}\left(a^{4}-b^{4}\right)+32 a^{2} b^{2}\left(a^{8}-b^{8}\right)+64 b^{4} a^{8} \ln \frac{b}{a}+ \\
& +144 a^{6} b^{6} \ln \frac{b}{a}+56 a^{2} b^{10} \ln \frac{b}{a}+352 a^{6} b^{6} \ln a^{2} b^{2}- \\
& -96 a^{2} b^{10} \ln a^{2} b^{2}+144 a^{8} b^{4} \ln a^{2} b^{2}+1024 a^{6} b^{6} \ln \frac{b^{3}}{a^{3}}+ \\
& +256 a^{4} b^{8} \ln \frac{b^{3}}{a^{3}}+768 a^{4} b^{8} \ln a \ln b-16 b^{12} \ln a^{2} b^{2}+ \\
& +32 b^{12} \ln a \ln b-384 a^{4} b^{8} \ln a^{2} b^{2}
\end{aligned}
$$

\subsection{Experimental Results}

The graphs of thrust force and the scanned images of delamination in drilling with and without support plate at a feed rate of $0.025 \mathrm{~mm} / \mathrm{rev}$, spindle speed of $1600 \mathrm{rpm}$ and drill point angle of $130^{\circ}$ are shown in Figure 4. It is believed that the thrust force applied by the drill on the specimen causes delamination and it occurs when the thrust force goes beyond its critical value. However, the graphs of the force in Figure 4 clearly indicate this is only true for drilling with a support plate. During unsupported drilling the force is lower than in supported drilling, whereas the delamination is more extensive, which suggests that in unsupported drilling a different mechanism is in play, and other factors must be considered. These factors can be the dynamics of the workpiece, and the way in which the force is applied.

The measured adjusted delamination factor $\left(F_{d a}\right)$ and the corresponding signal to noise ratio $(S N)$ determined using Taguchi method smaller is better for
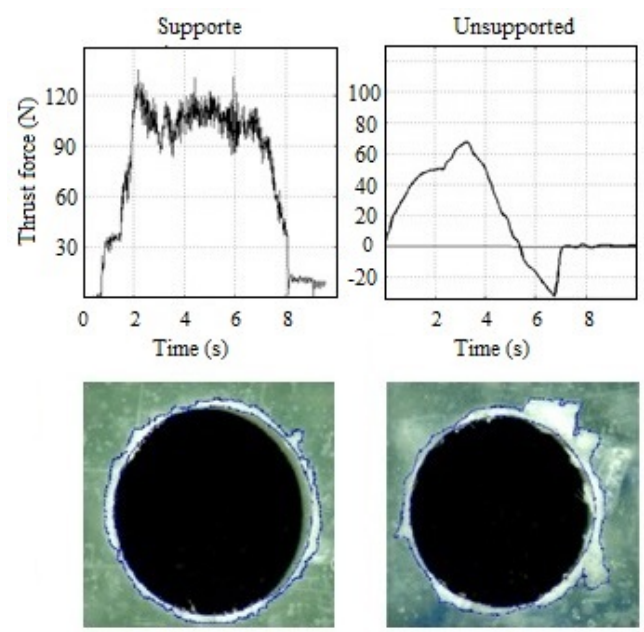

Figure 4. The graphs of thrust force and the scanned images of delamination in drilling with and without support plate.

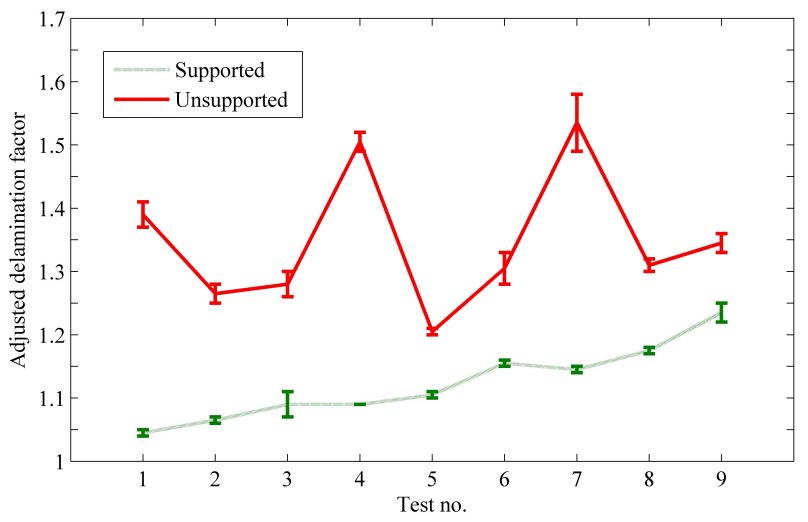

Figure 5. Comparison of $F_{d a}$ in drilling with and without back-up.

the two cases of drilling, supported and unsupported, are reported in Table 1.Symbols I and II in Table 1 represent two measured values for $F_{d a}$.

The t-test on the mean values of adjusted delamination factor demonstrates significant differences between the means in these two cases $\left(t_{0}=8.00>\right.$ $\left.t_{0.005,34}=2.73\right)$. To assist in the practical interpretation of this experiment, it is helpful to construct a graph of average responses at each experiment condition described in Table 1. This graph is shown in Figure 5. From Figure 5] a significant difference in adjusted delamination factor for supported drilling and unsupported drilling can be observed so that in all drilling tests, the average value of delamination is reduced when applying a back-up plate. This reduction is in the range of $8-27 \%$ for different drilling conditions. This reduction is mainly due to the reduction in matrix crack growth as a result of upward reaction of back-up plate.

The values of $S N$ data for the adjusted delamination factor for unsupported and supported drilling are given in Table 1 and shown in Figure 6. For unsupported drilling, the most important parame- 


\begin{tabular}{|c|c|c|c|c|c|c|c|c|c|}
\hline \multirow[t]{2}{*}{ Test no. } & \multicolumn{3}{|c|}{ Parameters } & \multicolumn{3}{|c|}{ Unsupported } & \multicolumn{3}{|c|}{ Supported } \\
\hline & Feed rate $(\mathrm{mm} / \mathrm{rev})$ & Speed (rpm) & Angle $\left(^{\circ}\right)$ & $F_{d a}(1)$ & $F_{d a}(2)$ & $S / N$ & $F_{d a}(1)$ & $F_{d a}(2)$ & $S / N$ \\
\hline 1 & 0.025 & 800 & 90 & 1.41 & 1.37 & -2.86 & 1.04 & 1.05 & -0.34 \\
\hline 2 & 0.025 & 1250 & 118 & 1.25 & 1.28 & -2.04 & 1.07 & 1.06 & -0.55 \\
\hline 3 & 0.025 & 1600 & 130 & 1.30 & 1.26 & -2.14 & 1.11 & 1.07 & -0.75 \\
\hline 4 & 0.05 & 800 & 118 & 1.49 & 1.52 & -3.55 & 1.09 & 1.09 & -0.87 \\
\hline 5 & 0.05 & 1250 & 130 & 1.20 & 1.21 & -1.62 & 1.10 & 1.11 & -1.25 \\
\hline 6 & 0.05 & 1600 & 90 & 1.33 & 1.28 & -2.31 & 1.16 & 1.15 & -0.75 \\
\hline 7 & 0.1 & 800 & 130 & 1.49 & 1.58 & -3.73 & 1.15 & 1.14 & -1.40 \\
\hline 8 & 0.1 & 1250 & 90 & 1.32 & 1.30 & -2.35 & 1.18 & 1.17 & -1.17 \\
\hline 9 & 0.1 & 1600 & 118 & 1.36 & 1.33 & -2.57 & 1.22 & 1.25 & -1.83 \\
\hline
\end{tabular}

TABLE 1. $L_{9}$ orthogonal array of Taguchi and experimental results.
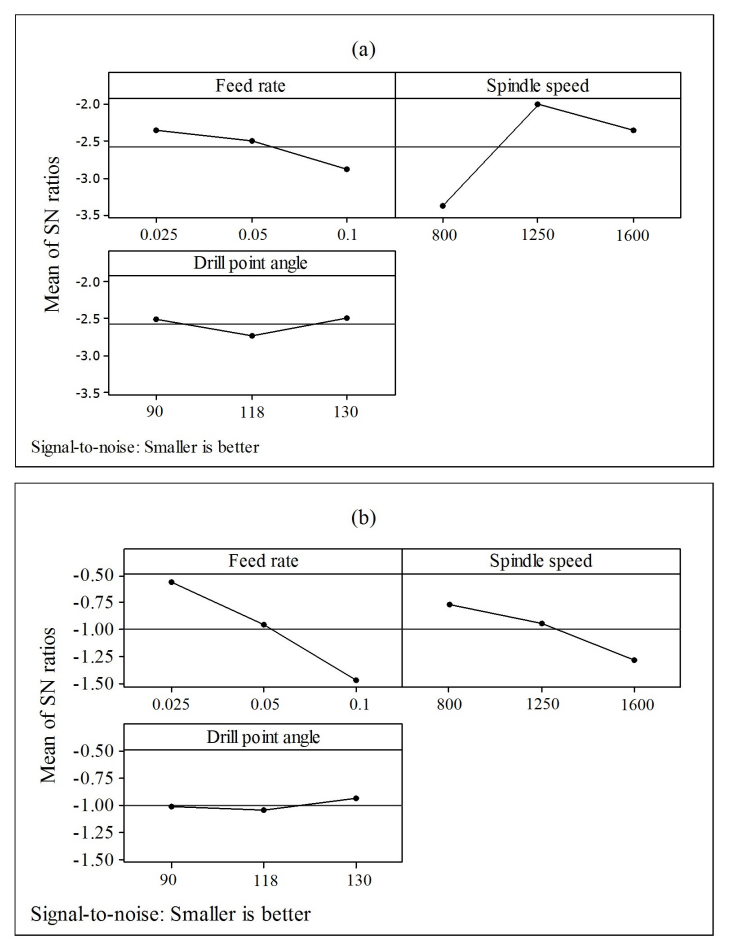

Figure 6. Effect of process parameters for (a) unsupported drilling, (b) supported drilling.

ters affecting the delamination factor are the spindle speed followed by feed rate. The optimum process parameters on the delamination are obtained as feed rate at level $1(0.025 \mathrm{~mm} / \mathrm{rev})$, spindle speed at level $2(1250 \mathrm{rpm})$ and drill point angle at level $3\left(130^{\circ}\right)$ when drilling without back-up plate. However, when the back-up plate is applied, the effect of feed rate on delamination increases so that it becomes the most important parameter followed by spindle speed, Figure 6 (b). The cause of this phenomenon can be attributed to the cutting mechanism and the relative movement of the tool and specimen. It is observed that the optimal value of the feed rate should be kept at low level in order to minimize the delamination factor. The optimum process parameters on the delamination are obtained as feed rate at level $1(0.025 \mathrm{~mm} / \mathrm{rev})$, spindle speed at level $1(800 \mathrm{rpm})$ and drill point angle at level $3\left(130^{\circ}\right)$ for supported drilling.

\section{Conclusions}

In this paper, the effect of exit support plate on delamination in drilling of glass fiber reinforced composites is studied. A comprehensive analysis of the critical thrust force in drilling with and without back-up plate is presented based on three theories i.e. energy conservation theory, elastic bending theory and linear elastic fracture mechanics. The experimental results confirm the effects of delamination reduction when using a back-up plate under the specimen. This reduction is in the range of $8-27 \%$ for different drilling conditions. This reduction is attributed to the crack growth suppression by upward reaction of back-up plate.

\section{REFERENCES}

[1] R. M. Jones. Mechanics of composite materials. CRC Press, 1998.

[2] D. Liu, Y. Tang, W. L. Cong. A review of mechanical drilling for composite laminatesc. Composite Structures 94(4):1265-1279, 2012.

[3] E. Capello. Workpiece damping and its effect on delamination damage in drilling thin composite laminates. Journal of Materials Processing Technology 148(1):186-95, 2004.

[4] H. Ho-Cheng, C. K. H. Dharan. Delamination during drilling in composite laminates. Journal of Manufacturing Science and Engineering 112(1):236-9, 1990.

[5] H. Hocheng, C. C. Tsao. Comprehensive analysis of delamination in drilling of composite materials with various drill bits. Journal of Materials Processing Technology 140(1):335-9, 2003.

[6] H. Hocheng, C. C. Tsao. Effects of special drill bits on drilling-induced delamination of composite materials. International Journal of Machine Tools and Manufacture 46(1):1403-16, 2006.

[7] H. Hocheng, C. C. Tsao. The path towards delamination-free drilling of composite materials. Journal of Materials Processing Technology 167(1):125164, 2005. DOI:10.1016/j.ijmachtools.2005.10.004.

[8] H. Hocheng, C. C. Tsao. Effects of exit back-up on delamination in drilling composite materials using a saw drill and a core drill. International Journal of Machine Tools and Manufacture 45(1):1261-70, 2005. 
[9] W.-C. Chen. Some experimental investigations in the drilling of carbon fiber-reinforced plastic (cfrp) composite laminates. International Journal of Machine Tools and Manufacture 37(1):1097-108, 1997.

[10] J. P. Davim, J. C. Rubio, A. M. Abrao. A novel approach based on digital image analysis to evaluate the delamination factor after drilling composite laminates. Composites Science and Technology 67(1):1939-45, 2007.

[11] N. Zarif Karimi, H. Heidary, M. Ahmadi. Residual tensile strength monitoring of drilled composite materials by acoustic emission. Materials and Design 40(1):229-36, 2012.

[12] N. Zarif Karimi, H. Heidary, G. Minak, M. Ahmadi. Effect of the drilling process on the compression behavior of glass/epoxy laminates. Composite Structures 98(1):5968, 2013. DOI:10.1016/j.compstruct.2012.10.044
[13] H. Heidary, N. Z. Karimi, M. Ahmadi, et al. Clustering of acoustic emission signals collected during drilling process of composite materials using unsupervised classifiers. Journal of Composite Materials 49(5):559-71, 2015. DOI:10.1177/0021998314521258

[14] N. Zarif Karimi, G. Minak, P. Kianfar. Analysis of damage mechanisms in drilling of composite materials by acoustic emission. Composite Structures 131(1):10714, 2015. DOI:10.1016/j.compstruct.2015.04.025

[15] R. K. Roy. A primer on the taguchi method, second edition. Society of Manufacturing Engineers, 2010.

[16] H. Saghizadeh, C. K. H. Dharan. Delamination fracture toughness of graphite and aramid epoxy composites. Journal of Engineering Materials and Technology 108(1):290-5, 1986.

[17] J. N. Reddy. Mechanics of laminated composite plates and shells: theory and analysis. CRC press, 2004. 